\title{
Retracted: Bayes Clustering and Structural Support Vector Machines for Segmentation of Carotid Artery Plaques in Multicontrast MRI
}

\author{
Computational and Mathematical Methods in Medicine
}

Received 9 February 2014; Accepted 9 February 2014; Published 10 March 2014

Copyright (C) 2014 Computational and Mathematical Methods in Medicine. This is an open access article distributed under the Creative Commons Attribution License, which permits unrestricted use, distribution, and reproduction in any medium, provided the original work is properly cited.

The paper titled "Bayes Clustering and Structural Support Vector Machines for Segmentation of Carotid Artery Plaques in Multicontrast MRI" [1], published in Computational and Mathematical Methods in Medicine, has been retracted upon the authors' request as it was found to include unreliable interpretation due to insufficient provision of studying materials.

\section{References}

[1] Q. Guan, B. Du, Z. Teng, J. Gillard, and S. Chen, "Bayes clustering and structural support vector machines for segmentation of carotid artery plaques in multicontrast MRI," Computational and Mathematical Methods in Medicine, vol. 2012, Article ID 549102, 6 pages, 2012. 